\title{
The characterization of creep and time-dependent properties of bulk metallic glasses using nanoindentation
}

\author{
W.H. Li ${ }^{\text {a,b,*}, \text { Keesam Shin }}{ }^{\text {b }}$, C.G. Lee ${ }^{\text {b }}$, B.C. Wei ${ }^{\text {c }}$, T.H. Zhang ${ }^{\text {d }}$, Y.Z. He ${ }^{\text {a }}$ \\ ${ }^{a}$ School of Materials Science and Engineering, Anhui University of Technology, 59 Hudong Road, Maanshan 243002, PR China \\ ${ }^{\mathrm{b}}$ School of Nano \& Advanced Materials Engineering, Changwon National University, Changwon 641-773, Republic of Korea \\ ${ }^{\mathrm{c}}$ National Microgravity Laboratory, Institute of Mechanics, Chinese Academy of Sciences, Beijing 100080, PR China \\ d State Key Laboratory of Nonlinear Mechanics, Institute of Mechanics, Chinese Academy of Sciences, Beijing 100080, PR China
}

Received 3 February 2007; received in revised form 5 June 2007; accepted 8 June 2007

\begin{abstract}
Viscoelastic deformation and creep behavior of La- and Ce-based bulk metallic glasses (BMGs) with low glass transition temperature are investigated through nanoindentation at room temperature. Creep compliance and retardation spectra are derived to study the creep mechanism. The time-dependent displacement can be well described by a generalized Kelvin model. A modification is proposed to determine the elastic modulus from the generalized Kelvin model. The results are in excellent agreement with the elastic modulus determined by uniaxial compression tests. (C) 2007 Published by Elsevier B.V.
\end{abstract}

Keywords: Nanoindentation; Bulk metallic glasses; Creep; A generalized Kelvin model

\section{Introduction}

The plastic deformation of metallic glasses is classified as homogeneous flow, where each volume element of the specimen contributes to the strain, or inhomogeneous flow, where the strain is localized to a few very thin shear bands [1]. At low strain rates and at high temperature $\left(T>0.7 T_{\mathrm{g}}\right)$, homogeneous flow will occur, whereas at high strain rate and low temperatures the flow is inhomogeneous. The dependence of the shear strain rate (or viscosity) on the temperature, time, structure relaxation, and the mechanism governing this dependence has been a most active area of research [2-5]. Isothermal creep testing is a popular means for studying viscoelastic deformation of bulk metallic glasses (BMGs). Conventional creep testing requires many samples and is therefore time consuming and inconvenient. In particular, due to sample-to-sample microstructure variation it is difficult to build models and study creep mechanisms.

\footnotetext{
* Corresponding author at: School of Materials Science and Engineering, Anhui University of Technology, 59 Hudong Road, Maanshan 243002, PR China. Tel.: +86 555 2311871; fax: +86555 2311570.

E-mail address: whli@imech.ac.cn (W.H. Li).
}

In recent years, nanoindentation has been proposed as a tool for the investigation of the behavior of materials, for example, during phase transformation, serrated flow, and creep [6]. Nanoindentation has been used successfully in the study of serrated flow by shear bands in BMGs [7-11]. However, to date little work for creep testing has been done on BMGs $[12,13]$. The majority of creep testing experiments using nanoindentation has been focused on polymers with low glass transition temperatures [14-18]. Their anisotropy and different macroscopic mechanical properties lead us to expect that polymers behave differently from BMGs during indentation. Compared with polymers, metallic glasses with isotropic structure and a wide supercooled liquid temperature region should be easier to study time-dependent deformation in particular their viscoelastic deformation, such as creep and relaxation in the amorphous state.

Rare-earth-based BMGs with $T_{\mathrm{g}}$ as low as La-, Nd-, Pr-, and especially Ce-based BMGs, have been developed [19-22]. This may allow creep experiments to be performed at room temperature, as the ratio of room temperature to $T_{\mathrm{g}}$ is higher than 0.8 in the case of Ce-based BMGs [22]. This is exactly the subject of this work, namely, creep and viscoelastic deformation of La- and Ce-based BMGs as induced by nanoindentation at room temperature. The time-dependent displacement can be described by a generalized Kelvin model. In addition, a modification of the 
Oliver-Pharr method is used also to calculate the elastic modulus of these alloys.

\section{Experimental}

\subsection{Materials}

Two kinds of La- and Ce-based BMGs, with a nominal composition of $\mathrm{La}_{60} \mathrm{Al}_{10} \mathrm{Ni}_{10} \mathrm{Cu}_{20}$ and $\mathrm{Ce}_{68} \mathrm{Al}_{10} \mathrm{Cu}_{20} \mathrm{Nb}_{2}$ (at\%), were used. These alloys were prepared by arc-melting La, Ce, $\mathrm{Al}, \mathrm{Ni}, \mathrm{Cu}$ and $\mathrm{Nb}$ with a purity of $99.9 \%$ in a titanium-gettered argon atmosphere. Cylindrical specimens of $3 \mathrm{~mm}$ in diameter and $70 \mathrm{~mm}$ in length were prepared by suction casting into a copper mold. The structure of the samples was characterized by X-ray diffraction (XRD) in a Philips PW 1050 diffractometer using $\mathrm{Cu} \mathrm{K} \alpha$ radiation. Thermal analysis was performed with a Perkin-Elmer DSC-7 differential scanning calorimeter under an argon atmosphere. A constant heating rate of $0.33 \mathrm{~K} / \mathrm{s}$ was employed.

\subsection{Nanoindentation procedures}

Nanoindentation experiments were conducted at room temperature $(296 \mathrm{~K})$ using a commercial depth-sensing instrument (MTS Nano Indenter ${ }^{\circledR}$ XP). All the indentation experiments were performed with a Berkovich diamond indenter. The specimens were mechanically polished to a mirror finish. Fused silica and aluminum were used as reference samples for the initial tip calibration procedure. For creep tests, specimens of $\mathrm{La}_{60} \mathrm{Al}_{10} \mathrm{Ni}_{10} \mathrm{Cu}_{20}$ and $\mathrm{Ce}_{68} \mathrm{Al}_{10} \mathrm{Cu}_{20} \mathrm{Nb}_{2}$ BMGs were loaded to $100 \mathrm{mN}$ at a loading rate of $20 \mathrm{mN} / \mathrm{s}$, held for $1000 \mathrm{~s}$, and then unloaded at the same rate as that during the loading. In addition, to investigate the effect of loading rate on the Young's modulus, experiments at constant loading rates of $0.03,0.075$, $0.2,0.5$ and $1 \mathrm{mN} / \mathrm{s}$ were performed to a depth limit $1000 \mathrm{~nm}$, and the maximum load was held constant for $10 \mathrm{~s}$ and then were unloaded at the rates as same as the loading one. Six indentations were made for each test on each specimen.

\section{Results and discussion}

Fig. 1 shows the XRD patterns and DSC curves of as-cast $\mathrm{La}_{60} \mathrm{Al}_{10} \mathrm{Ni}_{10} \mathrm{Cu}_{20}$ and $\mathrm{Ce}_{68} \mathrm{Al}_{10} \mathrm{Cu}_{20} \mathrm{Nb}_{2}$ samples. Both ascast alloys exhibit an XRD spectrum typical for the amorphous phase without an obvious crystalline peak. The glass transition temperature $\left(T_{\mathrm{g}}\right)$, crystallization temperature $\left(T_{\mathrm{x}}\right)$, and melting temperature $\left(T_{\mathrm{m}}\right)$ for the two BMGs measured by DSC are listed in Table 1. These values are in agreement previous measurements $[19,22]$.

Table 1

Glass transition temperature $\left(T_{\mathrm{g}}\right)$, crystallization temperature $\left(T_{\mathrm{x}}\right)$, melting temperature $\left(T_{\mathrm{m}}\right)$, Young's modulus $(E)$ and hardness $(H)$ for $\mathrm{Ce}_{68} \mathrm{Al}_{10} \mathrm{Cu}_{20} \mathrm{Nb}_{2}$ and $\mathrm{La}_{60} \mathrm{Al}_{10} \mathrm{Ni}_{10} \mathrm{Cu}_{20}$ alloys

\begin{tabular}{lcccll}
\hline Alloys & $T_{\mathrm{g}}(\mathrm{K})$ & $T_{\mathrm{X}}(\mathrm{K})$ & $T_{\mathrm{m}}(\mathrm{K})$ & $E(\mathrm{GPa})$ & $H(\mathrm{GPa})$ \\
\hline $\mathrm{Ce}_{68} \mathrm{Al}_{10} \mathrm{Cu}_{20} \mathrm{Nb}_{2}$ & 359 & 412 & 658 & 36.9 & 1.7 \\
$\mathrm{La}_{60} \mathrm{Al}_{10} \mathrm{Ni}_{10} \mathrm{Cu}_{20}$ & 405 & 445 & 659 & 41.2 & 2.2 \\
\hline
\end{tabular}

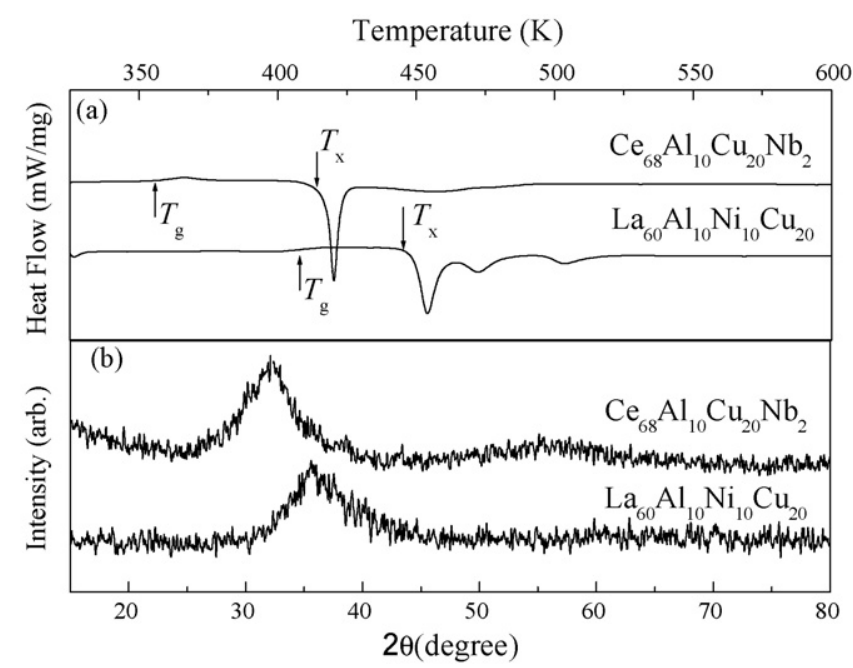

Fig. 1. (a) DSC curves and (b) XRD patterns of as-cast $\mathrm{Ce}_{68} \mathrm{Al}_{10} \mathrm{Cu}_{20} \mathrm{Nb}_{2}$ and $\mathrm{La}_{60} \mathrm{Al}_{10} \mathrm{Ni}_{10} \mathrm{Cu}_{20}$ alloys.

A high loading rate of $20 \mathrm{mN} / \mathrm{s}$ was chosen to minimize the viscoelastic deformation during the loading segment. The elastic modulus $(E)$ and the hardness $(H)$ of the two BMGs can be obtained using Oliver-Pharr method, and the results are also listed in Table 1. Fig. 2 shows creep displacement versus time for the La- and Ce-based BMGs. The curves were fit with a generalized Kelvin model [18], in which creep displacement can be expressed as

$h=h_{\mathrm{e}}+\sum_{i=1}^{n} h_{i}\left(1-\mathrm{e}^{-t / \tau_{i}}\right)$

where $h_{\mathrm{e}}$ is the indentation depth at the first spring, $h_{i}$ the indentation depth at the $i$ th Kelvin element, and $\tau_{i}$ is the retardation time for the $i$ th element. From Fig. 2 we can see that significant creep displacement is observed during the holding segment of the nanoindentation tests. The total creep displacement at this segment is 92 and $159 \mathrm{~nm}$ for $\mathrm{La}_{60} \mathrm{Al}_{10} \mathrm{Ni}_{10} \mathrm{Cu}_{20}$ and $\mathrm{Ce}_{68} \mathrm{Al}_{10} \mathrm{Cu}_{20} \mathrm{Nb}_{2} \mathrm{BMGs}$, respectively. The fitting parame-

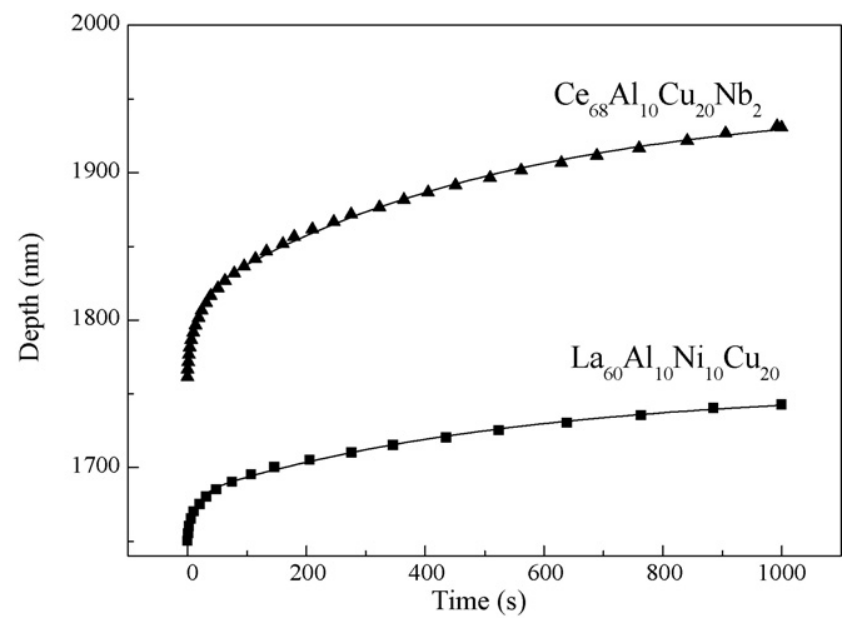

Fig. 2. Creep displacement vs. time for $\mathrm{Ce}_{68} \mathrm{Al}_{10} \mathrm{Cu}_{20} \mathrm{Nb}_{2}$ and $\mathrm{La}_{60} \mathrm{Al}_{10} \mathrm{Ni}_{10} \mathrm{Cu}_{20}$ BMGs. The data points are experimental data and solid lines are curves fitting by Eq. (1) with two exponential terms. 
Table 2

Fitting parameters in Eq. (1) for the two BMGs for a holding time of $1000 \mathrm{~s}$

\begin{tabular}{|c|c|c|c|c|c|c|}
\hline Alloys & $h_{\mathrm{e}}(\mathrm{nm})$ & $h_{1}(\mathrm{~nm})$ & $\tau_{1}(\mathrm{~s})$ & $h_{2}(\mathrm{~nm})$ & $\tau_{2}(\mathrm{~s})$ & Correlation coefficient \\
\hline $\mathrm{Ce}_{68} \mathrm{Al}_{10} \mathrm{Cu}_{20} \mathrm{Nb}_{2}$ & 1770.6 & 59.6 & 32.9 & 120.1 & 566.0 & 0.99987 \\
\hline $\mathrm{La}_{60} \mathrm{Al}_{10} \mathrm{Ni}_{10} \mathrm{Cu}_{20}$ & 1653.7 & 27.5 & 14.4 & 72.3 & 538.6 & 0.99974 \\
\hline
\end{tabular}

ters and correlation coefficients of the generalized Kelvin model are summarized in Table 2. The results show an excellent agreement between the experimental data and the fitting results. The retardation times, $\tau_{1}$ and $\tau_{2}$, are the different time responses that reflect the influence of the amorphous structure on the indentation load.

There are several other popular approaches to analyzing nanoindentation creep data. For example, Cheng et al. have recently published creep data on polymers and fit these data to a three-parameter linear viscoelastic model [23]. Beake et al. reported exact fitting of polymer creep data by a logarithmic relation [24]. Ngan and Tang have calculated creep data with an empirical exponential equation [25]. We find, however, that creep data of bulk metallic glasses can be fitted more accurately with the generalized Kelvin model.

From Fig. 2 we can also deduce the creep compliance, which can be approximately expressed as [26]

$$
J(t)=J_{0}+J_{1}\left(1-\mathrm{e}^{-t / \tau_{1}}\right)+J_{2}\left(1-\mathrm{e}^{-t / \tau_{2}}\right)
$$

where $J(t)$ is the creep compliance, $J_{0}\left(=1 / E_{0}\right)$ the instantaneous compliance without anelastic or viscoelastic deformation, and $E_{0}$ is the instantaneous elastic modulus. Fig. 3 shows that the creep compliance of two BMGs changes with holding time at constant loading. From Fig. 3 we see that compliance is initially constant and then increases with time. This increase in compliance is also found in amorphous polymers; it is usually referred to as a softening dispersion [27]. In amorphous alloys, the increase in compliance $(J)$ corresponds to the decrease in the elastic modulus $(E=1 / J)[28]$. As we know, the elastic modulus of a viscoelastic material includes two parts-the storage and loss modulus, which is usually nonlinear with respect to temperature, time and applied stress. In indentation creep testing,

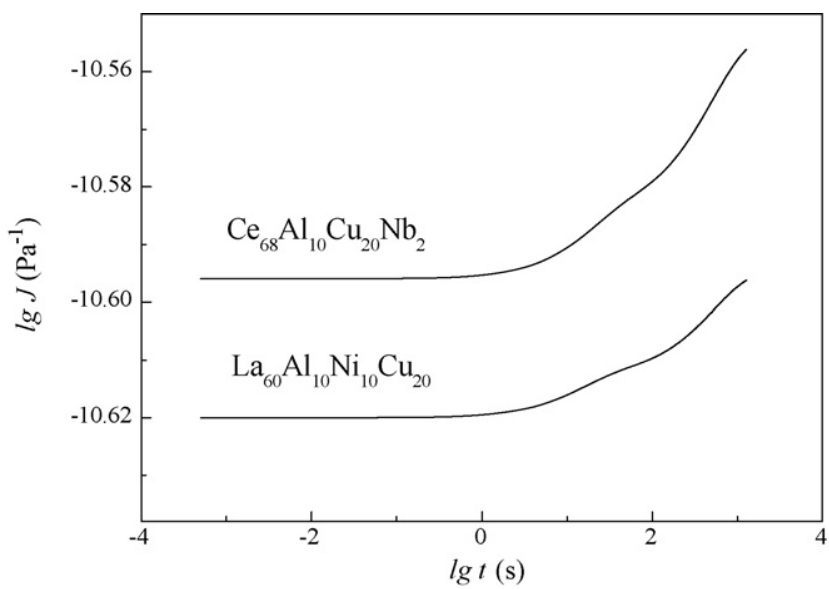

Fig. 3. Creep compliance vs. time for $\mathrm{Ce}_{68} \mathrm{Al}_{10} \mathrm{Cu}_{20} \mathrm{Nb}_{2}$ and $\mathrm{La}_{60} \mathrm{Al}_{10} \mathrm{Ni}_{10} \mathrm{Cu}_{20}$ BMGs. structure relaxation increases at constant load applied, resulting in the increasing compliance. Additionally, we notice that there are two inflexions in the creep compliance curves. This result was similar to that measured by rheometry [29].

The retardation spectra can be derived from [26]

$$
\begin{aligned}
L(\tau)= & {\left[\left(1+\frac{t}{\tau_{1}}\right) \frac{h_{1}}{\tau_{1}} \mathrm{e}^{-t / \tau_{1}}\right.} \\
& \left.+\left(1+\frac{t}{\tau_{2}}\right) \frac{h_{2}}{\tau_{2}} \mathrm{e}^{-t / \tau_{2}}\right]\left.\frac{A_{0}}{P_{0} h_{\text {in }}} t\right|_{t=2 \tau}
\end{aligned}
$$

Fig. 4 shows the retardation spectra for our two BMGs. Each creep relaxation spectrum consists of two peaks with welldefined relaxation times. This implies that there are two kinds of relaxation processes for La- and Ce-based BMGs during indentation creep at room temperature. The positions of the sharp retardation peaks indicate that the Ce-based BMG has a more relaxed state than the La-based BMGs, as affected also by its lower glass transition temperature [12]. The two broad retardation peaks suggest that the processes of the shear transformation have a distribution of free activation energies. Li and Warren propose that the stress fields in the specimen beneath the indenter create a chemical potential gradient that leads to a thermally activated diffusional flux of atoms [30]. Aklonis used two different relaxation times and a distribution of relaxation time near the glass transition or sub- $T_{\mathrm{g}}$ region [31]. van den Beukel and coworkers, in a series of papers on relaxation in amorphous alloys, proposed two relaxation processes based on the chemical short-range order (CSRO) and topologic short-range order (TSRO) [32]. These pathways were assumed to be separated in time. Obviously, further work is necessary to understand

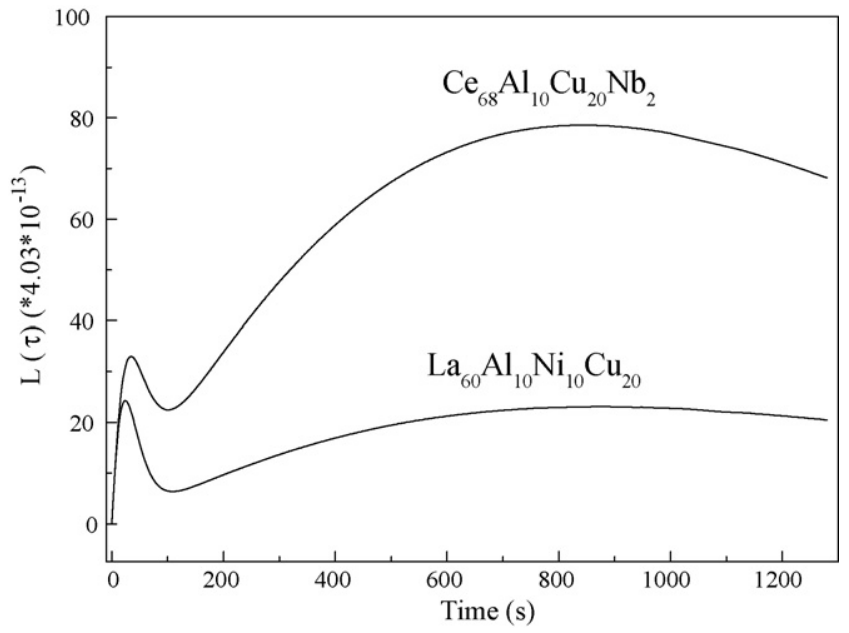

Fig. 4. Retardation spectra for $\mathrm{Ce}_{68} \mathrm{Al}_{10} \mathrm{Cu}_{20} \mathrm{Nb}_{2}$ and $\mathrm{La}_{60} \mathrm{Al}_{10} \mathrm{Ni}_{10} \mathrm{Cu}_{20} \mathrm{BMGs}$ from Eq. (3) derived from nanoindentation creep experiments. 
Table 3

Fitting parameters $h_{\mathrm{f}}, B, n, K_{1}, \tau_{1}, K_{2}, \tau_{2}$, and correlation coefficient of $\mathrm{Ce}_{68} \mathrm{Al}_{10} \mathrm{Cu}_{20} \mathrm{Nb}_{2}$ and $\mathrm{La}_{60} \mathrm{Al}_{10} \mathrm{Ni}_{10} \mathrm{Cu}_{20}$ alloys with $0.03 \mathrm{mN} / \mathrm{s}$ unloading rates

\begin{tabular}{lllllllll}
\hline Alloys & $h_{\mathrm{f}}(\mathrm{nm})$ & $A$ & $n$ & $K_{1}(\mathrm{mN} / \mathrm{nm})$ & $\tau_{1}(\mathrm{~s})$ & $K_{2}(\mathrm{mN} / \mathrm{nm})$ & $\tau_{2}(\mathrm{~s})$ & Correlation coefficient \\
\hline $\mathrm{Ce}_{68} \mathrm{Al}_{10} \mathrm{Cu}_{20} \mathrm{Nb}_{2}$ & 902 & 16.6 & 0.66 & 9.8 & 26.1 & 1.68 & 150.2 & 0.99976 \\
$\mathrm{La}_{60} \mathrm{Al}_{10} \mathrm{Ni}_{10} \mathrm{Cu}_{20}$ & 917 & 23.4 & 0.58 & 14.5 & 17.6 & 1.37 & 314.6 & 0.99985 \\
\hline
\end{tabular}

how these phenomena relate to the characteristics of the present BMGs.

We use the generalized Kelvin model to fit the unloading curves, to find the hardness and elastic moduli, applying the methodology of Oliver and Pharr [33,34]. In this method, the elastic modulus is obtained by assuming that the response to a deformation is a purely elastic recovery process. This neglects real viscoelastic properties that can be time-dependent and thus lead to an overestimation of Young's modulus. Fig. 5shows the load-displacement $(P-h)$ curves of the two BMGs at a loading rate of $0.03 \mathrm{mN} / \mathrm{s}$. The inset in Fig. 5 highlights the unloading segments in the two BMGs. We can see that the indentation depth continues to increase at the beginning of the unloading process, resulting in a "horn" or "nose" in the unloading curve. When the "nose" occurs, the stiffness at the unloading becomes negative, and the calculated elastic modulus may be unreasonable. The Oliver-Pharr method gives an elastic modulus $(E)$ of 65.5 and $60.6 \mathrm{GPa}$ for $\mathrm{La}_{60} \mathrm{Al}_{10} \mathrm{Ni}_{10} \mathrm{Cu}_{20} \mathrm{BMG}$ and $\mathrm{Ce}_{68} \mathrm{Al}_{10} \mathrm{Cu}_{20} \mathrm{Nb}_{2} \mathrm{BMG}$, respectively. These modulus values are nearly twice as high as those determined from compression tests [35], thus showing that Oliver-Pharr is not appropriate for a material with time-dependent responses.

The unloading curves include two parts, one is elastic recovery and another is viscoelastic recovery. We can use the Oliver-Pharr approximation for the purely elastic recovery part in which the indentation depth can be expressed by a power law as

$h_{\mathrm{e}}=h_{\mathrm{f}}+A P^{n}$

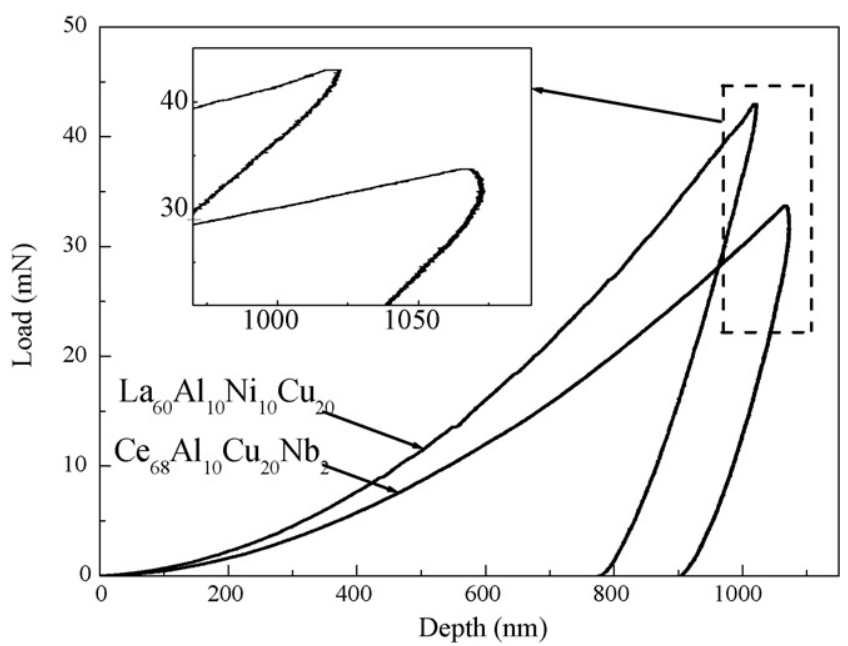

Fig. 5. Typical load-displacement $(P-h)$ curves of $\mathrm{Ce}_{68} \mathrm{Al}_{10} \mathrm{Cu}_{20} \mathrm{Nb}_{2}$ and $\mathrm{La}_{60} \mathrm{Al}_{10} \mathrm{Ni}_{10} \mathrm{Cu}_{20} \mathrm{BMGs}$ at a loading rate of $0.03 \mathrm{mN} / \mathrm{s}$. The inset highlights the unloading segments.

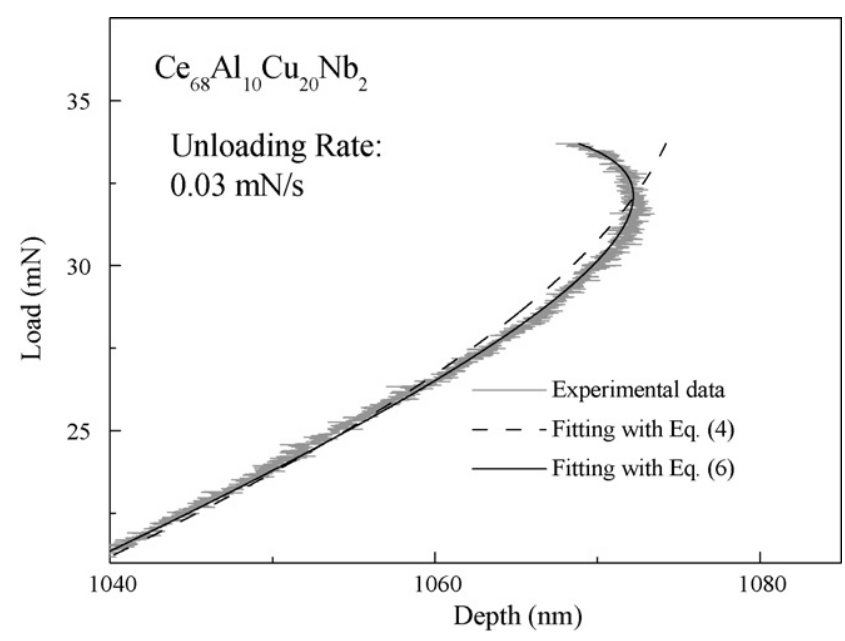

Fig. 6. The curve fitting of the unloading segment of $\mathrm{Ce}_{68} \mathrm{Al}_{10} \mathrm{Cu}_{20} \mathrm{Nb}_{2}$ with the Oliver-Pharr method and modified Oliver-Pharr method at an unloading rate of $0.03 \mathrm{mN} / \mathrm{s}$.

The viscoelastic recovery can be described via the generalized Kelvin model as

$h_{v}=\sum_{i=1}^{n} \frac{P}{K_{i}}\left(1-\mathrm{e}^{-t / \tau_{i}}\right)$

where $A, h_{\mathrm{f}}, n, K_{i}$ and $\tau_{i}$ are fitting constants. Thus, the total displacement during unloading can be described by

$h=h_{\mathrm{f}}+A P^{n}+\sum_{i=1}^{n} \frac{P}{K_{i}}\left(1-\mathrm{e}^{-t / \tau_{i}}\right)$

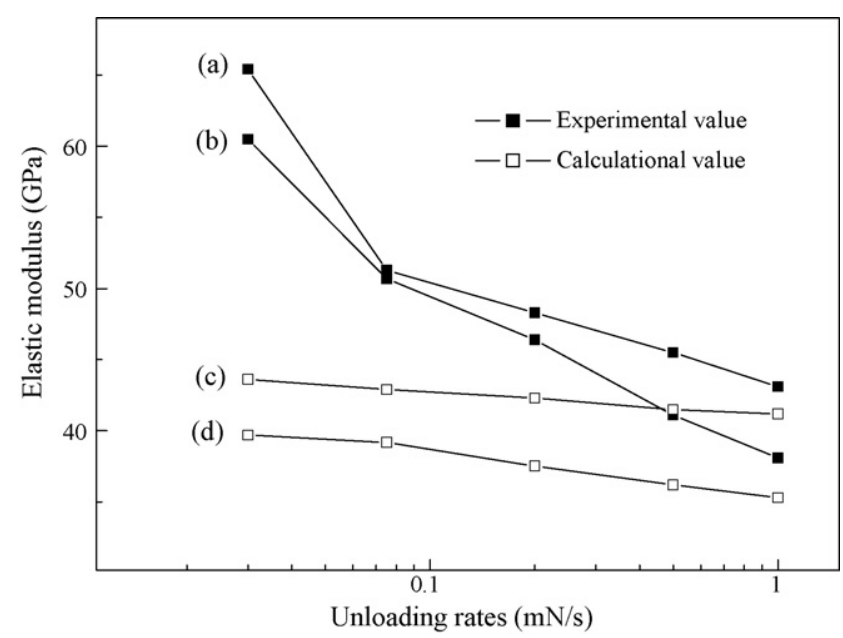

Fig. 7. Elastic modulus obtained using the Oliver-Pharr method for (a) $\mathrm{La}_{60} \mathrm{Al}_{10} \mathrm{Ni}_{10} \mathrm{Cu}_{20}$, (b) $\mathrm{Ce}_{68} \mathrm{Al}_{10} \mathrm{Cu}_{20} \mathrm{Nb}_{2}$ BMGs and the modified Oliver-Pharr method for, (c) $\mathrm{La}_{60} \mathrm{Al}_{10} \mathrm{Ni}_{10} \mathrm{Cu}_{20}$; and (d) $\mathrm{Ce}_{68} \mathrm{Al}_{10} \mathrm{Cu}_{20} \mathrm{Nb}_{2}$ BMGs, at different unloading rates. 
where $t=\left(P_{\max }-P\right) / \dot{P}, P_{\max }$ is the initial load of the unloading stages and $\dot{P}$ is the unloading rate. The indentation unloading curves of the Ce-based BMG and the fitted curves derived from Eq. (6) are shown in Fig. 6. The fitting parameters are summarized in Table 3 . Note the excellent correlation coefficients, seen also in Fig. 6.

Fig. 7 shows the elastic moduli calculated with our modified method and the simple Oliver-Pharr method at different loading rates. We see that the modulus calculated by the modified method is nearly independent of the loading rate and agrees with the value determined by compression tests. This suggests that our analysis method is indeed useful to derive the modulus of timedependent materials.

\section{Conclusion}

Creep and time-dependent deformation behavior in $\mathrm{La}_{60} \mathrm{Al}_{10} \mathrm{Ni}_{10} \mathrm{Cu}_{20}$ and $\mathrm{Ce}_{68} \mathrm{Al}_{10} \mathrm{Cu}_{20} \mathrm{Nb}_{2}$ BMGs have been investigated by nanoindentation at room temperature. The indentation creep can be described by a generalized Kelvin model. The creep relaxation spectrum reveals two separate peaks, which may relate to two kinds of relaxation processes. A modified Oliver-Pharr method is proposed to estimate the elastic modulus of these BMGs, and good agreement is found.

\section{Acknowledgements}

This research was carried out during a visit by the author to Changwon National University supported by the second stage of the Brain Korea 21 program. The authors would also like to acknowledge the support of the Korean Research Foundation, Grant (KRF-2006-005-J02703), the Nature Science Foundation of Anhui Educational Bureau (Grant No. KJ2007B273) and the National Nature Science Foundation of China (Grant No. 50571109).

\section{References}

[1] F. Spacepen, Acta Metall. 25 (1977) 407.

[2] H. Kato, A. Inoue, H.S. Chen, Appl. Phys. Lett. 79 (2001) 4515.
[3] W.L. Johnson, J. Lu, M.D. Demetriou, Intermetallics 10 (2002) 1039.

[4] M. Ohta, A.E. Berlev, V.A. Khonik, K. Kitagawa, Philo. Mag. 83 (2003) 3463.

[5] A.E. Berlev, O.P. Bobrov, V.A. Khonik, K. Csach, A. Juríková, J. Miškuf, H. Neuhäuser, M.Yu. Yazvitsky, Phys. Rev. B 68 (2003) 132203.

[6] A.C. Fischer-Cripps, Nanoindentation, Springer-Verlag, NY, 2002.

[7] C.A. Schuh, T.G. Nieh, Acta Mater. 51 (2003) 87.

[8] T.G. Nieh, C. Schuh, J. Wadsworth, Y. Li, Intermetallics 10 (2002) 1177.

[9] W.H. Jiang, M. Atzmon, J. Mater. Res. 18 (2003) 755.

[10] B.C. Wei, T.H. Zhang, W.H. Li, Y.F. Sun, Y. Yu, Y.R. Wang, Intermetallics 12 (2004) 1239.

[11] W.H. Li, T.H. Zhang, D.M. Xing, B.C. Wei, Y.D. Dong, J. Mater. Res. 21 (2006) 75

[12] B.C. Wei, T.H. Zhang, W.H. Li, L.C. Zhang, Y.R. Wang, Mater. Trans. 46 (2005) 2959.

[13] A. Concustell, J. Sort, A.L. Greer, M.D. Baro, Appl. Phys. Lett. 88 (2006) 171911.

[14] B.J. Briscoe, L. Fiori, E. Pelillo, J. Phys. D 31 (1998) 2395.

[15] A. Strojny, W.W. Gerberich, Mater. Res. Soc. Symp. Proc. 522 (1998) 159.

[16] J.C.M. Li, Mater. Sci. Eng. A 322 (2002) 23.

[17] M.L. Oyen, R.F. Cook, J. Mater. Res. 18 (2003) 139.

[18] Y. Shuang, Y.W. Zhang, K.Y. Zeng, J. Appl. Phys. 95 (2004) 3655.

[19] A. Inoue, T. Zhang, T. Masumoto, Mater. Trans. JIM 30 (1990) 425.

[20] Y. He, C.E. Price, S.J. Poon, G.J. Shiflet, Philos. Mag. Lett. 70 (1994) 371.

[21] Z.F. Zhao, P. Wen, M.X. Pan, D.Q. Zhao, W.H. Wang, Appl. Phys. Lett. 82 (2003) 4699.

[22] B. Zhang, M.X. Pan, D.Q. Zhao, W.H. Wang, Appl. Phys. Lett. 85 (2004) 61.

[23] J.D. Ferry, Viscoelastic Properies of Polymers, 3rd ed., Wiley, New York, 1980.

[24] L. Cheng, X. Xia, L.E. Scriven, W.W. Gerberich, Mech. Mater. 37 (2005) 213.

[25] B.D. Beake, J. Phys. D 39 (2006) 4478.

[26] A.H.W. Ngan, B. Tang, J. Mater. Res. 17 (2002) 2604.

[27] K.M. Bernatz, I. Echeverria, S.L. Simon, D.J. Plazek, J. Non-Cryst. Solids 307-310 (2002) 790.

[28] L.C. Zhang, B.C. Wei, D.M. Xing, T.H. Zhang, W.H. Li, Y. Liu, Intermetallics 15 (2007) 791.

[29] V.A. Khonik, A.T. Kosilov, V.A. Mikhailov, V.V. Sviridov, Acta Mater. 46 (1998) 3399.

[30] W.B. Li, R. Warren, Acta Metall. Mater. 41 (1993) 3065.

[31] J.J. Aklonis, A.J. Kovacs, Contemp. Top. Polym. Sci. 3 (1979) 267.

[32] V. Ocelík, K. Csach, A. Kasardová, V.Z. Bengus, Mater. Sci. Eng. A 226-228 (1997) 851.

[33] W.C. Oliver, G.M. Pharr, J. Mater. Res. 7 (1992) 1564.

[34] G.M. Pharr, W.C. Oliver, F.B. Brotzen, J. Mater. Res. 7 (1992) 613.

[35] B.C. Wei, T.H. Zhang, L.C. Zhang, D.M. Xing, W.H. Li, Y. Liu, Mater. Sci. Eng. A 449-451 (2007) 962. 